\title{
One-step synthesis of ordered mesostructural organic/silica nanocomposites with tunable fluorescence surfactants
}

\author{
Hsiung-Lin Tu, ${ }^{a}$ Fu-Yu Tsai ${ }^{* b}$ and Chung-Yuan Mou ${ }^{a c}$ \\ Received 3rd January 2008, Accepted 30th January 2008 \\ First published as an Advance Article on the web 19th February 2008 \\ DOI: 10.1039/b800070k
}

\begin{abstract}
Mesostructured nanocomposites with tunable fluorescence were prepared by one-step synthesis using fluorescent surfactants with 1,2 and 3 units of thiophene as templates. The XRD data showed that the resulting nanocomposites exhibited ordered mesostructures, which could be further confirmed by TEM observation. Moreover, the surfactants with longer hydrophobic chain lengths result in mesostructured nanocomposites with larger lattice constants. Fluorescent properties of these nanocomposites, compared with the same fluorescent surfactants in other environments, showed fluorescence bands that were red-shifted in the fluorescence spectra. $\mathrm{N}_{2}$ adsorption-desorption experiments indicated that the rearrangement of PEO chains and the conjugated part of surfactants occurs upon hydrothermal treatment, thus enlarging the pore diameter, surface area and pore volume of the resulting mesostructured nanocomposites.
\end{abstract}

\section{Introduction}

Functional nanocomposites are currently a subject of great interest because of their unique properties, which are a result of the suitable combination of organic and inorganic phases. ${ }^{1}$ Mesoporous materials made by surfactant-directed self assembly (SDSA) have long been used as ideal inorganic hosts for nanocomposites, as they can provide a tunable ordered mesostructure. In the past decade, there have been numerous reports showing that functional nanocomposites could enhance the conductivity, mechanical strength, environmental stability and photoluminescence of the resulting materials. ${ }^{2}$ With a built-in chromophore functional group, it seems that they might also have great potential for optical and electronic applications. ${ }^{3}$

We are interested, in particular, in an ordered mesostructural organic/silica nanocomposite with tunable fluorescence surfactants. The mesoporous silica channels inside this material have the potential to allow greater control over the molecular alignment and stability. Furthermore, the nanochannel is also an ideal host for the fluorescent molecules used to study its photoluminescence (PL) in a confined space. ${ }^{4}$ Several groups ${ }^{5,6}$ have reported the red-shifted fluorescence band of a conjugated polymer located inside the mesoporous silicate channel as compared with a neat conjugated polymer, the interpretation of which was related to the longer effective $\pi$-conjugation length of the conjugated polymer in a confined space.

On the other hand, it has been reported that mesostructured nanocomposites with optoelectronic properties can be prepared by several methods, including post-loading, ${ }^{7,8}$ co-condensation, ${ }^{9,10}$ template-assisted polymerization, ${ }^{6,11,12}$ and other

${ }^{a}$ Department of Chemistry, National Taiwan University, Taipei, 106, Taiwan

${ }^{b}$ Institute of Organic and Polymeric Materials, National Taipei University of Technology, Taipei, 106, Taiwan

${ }^{c}$ Center for Condensed Matter Sciences, National Taiwan University, Taipei, 106, Taiwan methods. ${ }^{5,13-16}$ In a post-synthesis approach, Tolbert et al. $^{7}$ reported the preparation of PL polymer/silica composites by post-synthesis of poly[2-methoxy-5-(2'-ethyl-hexyloxy)-1,4phenylene]vinylene (MEH-PPV) into pre-formed mesoporous silicate channels. Energy-transfer ${ }^{9}$ and lasing behavior ${ }^{10}$ were observed in functionalized mesoporous materials obtained by the co-condensation method. More recently, Tolbert et al. reported a one-step synthesis of periodic nanoscale silica composite materials by using amphiphilic poly(phenylene ethynylene) (PPE) and cetyltrimethylammonium bromide (CTAB) as the co-surfactant system. ${ }^{17}$ For the post-synthesis method, however, multiple procedures are needed in order to obtain functional mesostructured nanocomposites. In the co-condensation approach, the number of aligned fluorescent molecules inside the mesoporous silica is usually low.

Hence, a better strategy to meet the goal of complete pore filling might be the preparation of polymerizable surfactants for the mesostructured nanocomposites. In fact, such an approach (called template-assisted polymerization) has already been demonstrated by Aida and Tajima ${ }^{6}$ and Brinker et al.; ${ }^{11}$ it refers to the use of diacetylenic surfactants as templates for the synthesis of the mesostructured nanocomposites, and then the application of a polymerization process by thermal or phototreatment. The resulting nanocomposites, which contained polydiacetylene inside the nanochannels, showed unique thermo-, mechano- and solvatochromic properties. ${ }^{11}$ Although this approach guarantees a dense filling of conjugated polymer, further thermal or photo-treatment is still necessary in order to obtain nanocomposites with optoelectronic properties. Very recently, Bhongale and $\mathrm{Hsu}^{18}$ reported the emission enhancement properties of relatively disordered chromophoric surfactant amphiphile/silica nanocomposites. Compared with the solid state, the nanocomposites showed about a fourteenfold increase in the PL intensity, which was attributed to the well-ordered arrangement of the chromophore groups in the nanochannels. 
Nonionic oligomeric surfactants with poly(ethylene oxide) (PEO) as the hydrophilic block for the synthesis of well-ordered mesoporous silica was first reported by Stucky et al. ${ }^{19}$ The assembly of the inorganic and organic components appears to take place via a hydrogen bonding pathway. These kinds of oligomeric surfactants can have different hydrophobic blocks such as diacetylenes, ${ }^{11}$ alkyl chains,${ }^{20}$ poly(methyl acrylate) ${ }^{21}$ and diphenylpyreneamine. ${ }^{22}$ So it seems reasonable to vary the hydrophobic block of oligomeric surfactants for mesoporous materials, with PEO acting as the hydrophilic portion. Polythiophene is one of the most widely investigated model systems for the design of small bandgap linear $\pi$-conjugated systems due to its electronic properties, environmental stability and structural versatility. ${ }^{23}$ Therefore, we chose thiophene as a building block in the hydrophobic part of the surfactants.

In our previous work, ${ }^{24}$ we briefly reported the preparation of mesostructured nanocomposites with pore-filling fluorescent molecules. The brightness of the nanocomposites is greater and the emission wavelength is red-shifted as compared with those of the free surfactant. However, the confinement effect for the red-shift and enhancement of spectral intensity was not clear. Here, we report a study of a fluorescent surfactant system consisting of variable oligothiophene as the hydrophobic part. We began by tuning the conjugated system of fluorescent surfactants and then used these directly to guide the synthesis of nanocomposites with yellow or orange fluorescence. The variation in fluorescent chain length allows us to study the effects of confinement in more detail. Furthermore, as polythiophene is known for its relatively low fluorescent brightness, ${ }^{25}$ we expected that the brightness of the resulting composites might also be enhanced based on our previous results. First, the fluorescent surfactants containing 1, 2 and 3 co-condensed thiophene units were successfully synthesized by multi-step reactions. After the sol-gel process, we successfully obtained mesostructured nanocomposites. The pore diameter (lattice constant) and fluorescence properties of the resulting nanocomposites depend upon the chosen surfactants. In addition, we found that hydrothermal treatment also affects the fluorescence properties of these nanocomposites.

\section{Experimental}

\section{General information and characterization techniques}

All reactions involving air- or moisture-sensitive conditions were carried out in a dry nitrogen atmosphere. $\mathrm{Et}_{2} \mathrm{O}$ and $\mathrm{THF}$ were distilled from sodium benzophenone ketyl. Chemicals were purchased from commercial suppliers and were used without further purification.

The powder X-ray diffraction patterns were acquired on a PANalytical X'Pert PRO $(45 \mathrm{kV}, 40 \mathrm{~mA})$ with $\mathrm{CuK}_{\alpha}$ radiation $(\lambda=0.1541 \mathrm{~nm}) . \mathrm{N}_{2}$ adsorption-desorption isotherms were obtained at $77 \mathrm{~K}$ on a Micromeritics ASAP 2010 analyzer. Before sorption measurements, the calcined samples were degassed at $150{ }^{\circ} \mathrm{C}$ for more than $6 \mathrm{~h}$ under $10^{-3}$ Torr pressure. TEM images were recorded on a Hitachi H-7100 operating at an acceleration voltage of $100 \mathrm{kV}$ and a FEI Tecnai $\mathrm{G}^{2}$ operating at an acceleration voltage of $200 \mathrm{kV}$. UV/Vis spectra were recorded on a Hitachi U-3310 spectrophotometer. Fluorescence spectra were recorded in reflection mode on a Fluorolog Tau-3 spectrophotometer with attachments for powder samples. ${ }^{1} \mathrm{H}$ and ${ }^{13} \mathrm{C}$ NMR spectra were recorded in $\mathrm{CDCl}_{3}$ solution at $25^{\circ} \mathrm{C}$ on a Varian 400 NMR spectrometer.

\section{Synthesis of the fluorescent surfactants}

Compound 2-oct-1-ynethiophene (1), ${ }^{26}$ 2-iodo-5-oct-1-ynethiophene (2), ${ }^{27}$-iodo-[2,2']-bithiophenyl (3) ${ }^{28}$ and 2-thienylboronic $\operatorname{acid}^{29}$ were prepared according to the published procedures.

5-Oct-1-ynyl-[2,2']-bithiophenyl (4). Under a nitrogen atmosphere, a Schlenk tube was charged with 5-iodo-[2,2']-bithiophenyl 3 (3.0 g, $10.3 \mathrm{mmol})$, 1-octyne (1.3 g, $11.9 \mathrm{mmol}), \mathrm{Pd}\left(\mathrm{PPh}_{3}\right)_{4}$ (0.12 g, $0.1 \mathrm{mmol})$, CuI (0.039 g, $0.2 \mathrm{mmol})$, THF $(30 \mathrm{~mL})$ and $\mathrm{NEt}_{3}(15 \mathrm{~mL})$. The reaction mixture was stirred at $50{ }^{\circ} \mathrm{C}$ for $24 \mathrm{~h}$, and the resulting solution was passed through a short silica gel column with THF as the eluent to remove the ammonium salt. The solvent was evaporated to dryness and the crude product was purified by column chromatography (silica gel, hexane) to yield $2.2 \mathrm{~g}(78 \%)$ of the title compound as a brownish liquid. ${ }^{1} \mathrm{H}$ NMR $\left(\mathrm{CDCl}_{3}, 400 \mathrm{MHz}\right): \delta 7.19(\mathrm{~m}, 1 \mathrm{H}), 7.13(\mathrm{~m}, 1 \mathrm{H}), 6.99$ $(\mathrm{m}, 3 \mathrm{H}), 2.43(\mathrm{t}, J=7.2 \mathrm{~Hz}, 2 \mathrm{H}), 1.60(\mathrm{~m}, 2 \mathrm{H}), 1.45(\mathrm{~m}, 2 \mathrm{H})$, $1.33(\mathrm{~m}, 4 \mathrm{H}), 0.91(\mathrm{t}, J=2.8 \mathrm{~Hz}, 3 \mathrm{H}) .{ }^{13} \mathrm{C} \mathrm{NMR}\left(\mathrm{CDCl}_{3}, 100\right.$ $\mathrm{MHz}): \delta$ 137.4, 137.0, 131.8, 127.9, 124.7, 124.0, 123.4, 123.2, 96.0, 74.2, 32.2, 29.5, 29.4, 23.4, 20.7, 15.0. HRMS: $\mathrm{m} / \mathrm{z}$ calcd for $\mathrm{C}_{16} \mathrm{H}_{18} \mathrm{~S}_{2}, 274.0850$; found, 274.0856.

5-Iodo-5' -oct-1-ynyl-[2,2']-bithiophenyl (5). $n$-BuLi (5.5 mL, 18 mmol) was added to a solution of 5-oct-1-ynyl-[2,2']-bithiophenyl 4 (4.5 g, $16.4 \mathrm{mmol})$ in dried $\mathrm{Et}_{2} \mathrm{O}(35 \mathrm{~mL})$ with stirring under nitrogen at $0{ }^{\circ} \mathrm{C}$. The solution was warmed to room temperature and stirred for an additional $2 \mathrm{~h}$ and then cooled to $-78{ }^{\circ} \mathrm{C} . \mathrm{I}_{2}(4.57 \mathrm{~g}, 18 \mathrm{mmol})$ was added into the reaction mixture with vigorous stirring and allowed to warm to room temperature for $6 \mathrm{~h}$, quenched with ice water and extracted with $\mathrm{Et}_{2} \mathrm{O}$. The combined organic solution was washed with saturated $\mathrm{Na}_{2} \mathrm{~S}_{2} \mathrm{O}_{3}$, dried over $\mathrm{MgSO}_{4}$, and evaporated. The residue was purified by column chromatography (silica gel, hexane) to give $4.9 \mathrm{~g}(75 \%)$ of a yellow liquid. ${ }^{1} \mathrm{H}$ NMR $\left(\mathrm{CDCl}_{3}, 400 \mathrm{MHz}\right): \delta 7.12(\mathrm{~d}, J=3.6 \mathrm{~Hz}, 1 \mathrm{H}), 6.96(\mathrm{~d}, J=$ $4.0 \mathrm{~Hz}, 1 \mathrm{H}), 6.91(\mathrm{~d}, J=3.6 \mathrm{~Hz}, 1 \mathrm{H}), 6.79(\mathrm{~d}, J=4.0 \mathrm{~Hz}, 1$ $\mathrm{H}), 2.41(\mathrm{t}, J=6.8 \mathrm{~Hz}, 2 \mathrm{H}), 1.58(\mathrm{~m}, 2 \mathrm{H}), 1.42(\mathrm{~m}, 2 \mathrm{H})$, $1.30(\mathrm{~m}, 4 \mathrm{H}), 0.89(\mathrm{t}, J=6.4 \mathrm{~Hz}, 3 \mathrm{H}) .{ }^{13} \mathrm{C} \mathrm{NMR}\left(\mathrm{CDCl}_{3}\right.$, $100 \mathrm{MHz}): \delta$ 142.3, 137.2, 135.6, 131.3, 124.8, 123.3, 108.9, 96.1, 73.5, 72.2, 31.7, 29.0, 28.8, 22.9, 20.2, 14.5. HRMS: $\mathrm{m} / \mathrm{z}$ calcd for $\mathrm{C}_{16} \mathrm{H}_{17} \mathrm{IS}_{2}, 399.9816$; found, 399.9808 .

5-Oct-1-yne-[2,2'; $\left.\mathbf{5}^{\prime}, \mathbf{2}^{\prime \prime}\right]$-terthiophene (6). 5-Iodo-5'-oct-1-ynyl[2,2']-bithiophenyl 5 (3.0 g, $7.5 \mathrm{mmol})$, 2-thienylboronic acid $(1.39 \mathrm{~g}, 10.87 \mathrm{mmol}), \mathrm{K}_{2} \mathrm{CO}_{3}(2.07 \mathrm{~g}, 15 \mathrm{mmol})$ and $\mathrm{Pd}\left(\mathrm{PPh}_{3}\right)_{4}$ $\left(0.195 \mathrm{~g}, 1.7 \times 10^{-1} \mathrm{mmol}\right)$ were placed in a Schlenk tube, then dimethoxyethane (DME) $(28 \mathrm{~mL})$ and $\mathrm{H}_{2} \mathrm{O}(7 \mathrm{~mL})$ were charged into the reactor. The solution was stirred at $60^{\circ} \mathrm{C}$ for $12 \mathrm{~h}$. After cooling to room temperature, the reaction mixture was extracted with hexane, dried over $\mathrm{MgSO}_{4}$ and evaporated. The residue was purified by column chromatography (silica gel, hexane) to yield $2.33 \mathrm{~g}(87 \%)$ of a light yellow liquid. ${ }^{1} \mathrm{H}$ NMR $\left(\mathrm{CDCl}_{3}, 400\right.$ MHz): $\delta 7.20(\mathrm{~m}, 1 \mathrm{H}), 7.15(\mathrm{~m}, 1 \mathrm{H}), 7.05-6.96(\mathrm{~m}, 5 \mathrm{H}), 2.43$ 
(t, $J=7.2 \mathrm{~Hz}, 2 \mathrm{H}), 1.59(\mathrm{~m}, 2 \mathrm{H}), 1.43(\mathrm{~m}, 2 \mathrm{H}), 1.33(\mathrm{~m}, 4 \mathrm{H})$, $0.91(\mathrm{t}, J=6.8 \mathrm{~Hz}, 3 \mathrm{H}) .{ }^{13} \mathrm{C} \mathrm{NMR}\left(\mathrm{CDCl}_{3}, 100 \mathrm{MHz}\right): \delta 136.6$, $136.5,136.0,135.2,131.4,127.5,124.2,124.1,123.9,123.4$, $122.81,122.79,95.9,73.7,31.7,29.0,28.8,22.9,20.2,14.5$. HRMS: $m / z$ calcd for $\mathrm{C}_{20} \mathrm{H}_{20} \mathrm{~S}_{3}, 356.0727$; found, 356.0725.

$5^{\prime \prime}$-Iodo-5-oct-1-ynyl-[2, $\left.2^{\prime} ; 5^{\prime}, 2^{\prime \prime}\right]$ Terthiophene (7). Refer to the procedure for the synthesis of 5; compound $\mathbf{7}$ was obtained in $72 \%$ yield as a yellow liquid. ${ }^{1} \mathrm{H} \mathrm{NMR}\left(\mathrm{CDCl}_{3}, 400 \mathrm{MHz}\right)$ : $\delta 7.13(\mathrm{~d}, J=3.6 \mathrm{~Hz}, 1 \mathrm{H}), 7.01-6.95(\mathrm{~m}, 4 \mathrm{H}), 6.81(\mathrm{~d}, J=$ $3.6 \mathrm{~Hz}, 1 \mathrm{H}), 2.42(\mathrm{t}, J=7.2 \mathrm{~Hz}, 2 \mathrm{H}), 1.57(\mathrm{~m}, 2 \mathrm{H}), 1.42(\mathrm{~m}$, $2 \mathrm{H}), 1.31(\mathrm{~m}, 4 \mathrm{H}), 0.91(\mathrm{t}, J=6.4 \mathrm{~Hz}, 3 \mathrm{H}) .{ }^{13} \mathrm{C} \mathrm{NMR}$ $\left(\mathrm{CDCl}_{3}, 100 \mathrm{MHz}\right): \delta 142.4,137.3,136.3,135.8,134.7,131.4$, 124.7, 124.4, 124.1, 123.1, 123.0, 96.1, 73.6, 72.1, 31.7, 29.0, 28.8, 23.0, 20.2, 14.5. HRMS: $\mathrm{m} / z$ calcd for $\mathrm{C}_{20} \mathrm{H}_{19} \mathrm{IS}_{3}$, 481.9694; found, 481.9695 .

Compound 8. Poly(ethylene glycol) monomethyl ether $\left(M_{\mathrm{w}}=\right.$ $750,10 \mathrm{~g}, 13.3 \mathrm{mmol}$ ) was dried under vacuum at $100{ }^{\circ} \mathrm{C}$ for 2 h. After cooling to room temperature, $40 \mathrm{~mL}$ of dried $\mathrm{THF}$ and $\mathrm{NaH}(0.39 \mathrm{~g}, 16.4 \mathrm{mmol})$ were added at $0{ }^{\circ} \mathrm{C}$. The mixture was stirred at room temperature for $12 \mathrm{~h}$, then propargyl bromide (2.06 g, $17.3 \mathrm{mmol}$ ) was added and the solution was stirred for $4 \mathrm{~h}$ at room temperature. The resulting solution was passed through a short silica gel column with THF as the eluent. The clear solution was evaporated to dryness and then redissolved in $\mathrm{MeOH}$ with a small amount of water. The alcoholic solution was extracted with hexane to remove excess propargyl bromide. $\mathrm{MeOH}$ was then evaporated and $\mathrm{Et}_{2} \mathrm{O}$ was added, and the mixture was dried over $\mathrm{MgSO}_{4}$. After filtration and evaporation of $\mathrm{Et}_{2} \mathrm{O}, \mathbf{8}$ was obtained as a yellow viscous oil in $75 \%$ yield. ${ }^{1} \mathrm{H}$ NMR $\left(\mathrm{CDCl}_{3}, 400 \mathrm{MHz}\right): \delta 4.14$ (d, $J=$ $2.4 \mathrm{~Hz}, 2 \mathrm{H}$ ), 3.6 (br, $\left.\mathrm{OCH}_{2} \mathrm{CH}_{2} \mathrm{O}\right), 3.3\left(\mathrm{~s}, 3 \mathrm{H}, \mathrm{OCH}_{3}\right), 2.4(\mathrm{t}$, $J=2.4 \mathrm{~Hz}, 1 \mathrm{H}) .{ }^{13} \mathrm{C} \mathrm{NMR}\left(\mathrm{CDCl}_{3}, 100 \mathrm{MHz}\right): \delta 79.5,74.5$, 71.8-69.0 $\left(\mathrm{OCH}_{2} \mathrm{CH}_{2} \mathrm{O}\right)$, 59.0, 58.4. FAB-MS: $m / z$ : $797.7[\mathrm{M}+$ $\mathrm{Na}]^{+}$(calcd 797.5).

1t-PEO. A mixture of 8 (2.5 g, $3.2 \mathrm{mmol}), \mathrm{Pd}\left(\mathrm{PPh}_{3}\right)_{4}(0.074 \mathrm{~g}$, $\left.6.4 \times 10^{-2} \mathrm{mmol}\right)$ and $\mathrm{CuI}\left(0.024 \mathrm{~g}, 1.28 \times 10^{-1} \mathrm{mmol}\right)$ in $35 \mathrm{~mL}$ of dried THF was added to $2(1.26 \mathrm{~g}, 4 \mathrm{mmol})$ and $\mathrm{NEt}_{3}(20 \mathrm{~mL})$. The reaction mixture was stirred at $40^{\circ} \mathrm{C}$ for $24 \mathrm{~h}$ and the resulting solution passed through a short silica gel column with THF as the eluent to remove the ammonium salt. The solution was evaporated to dryness and then redissolved in $\mathrm{MeOH}$ with a small amount of water. The alcoholic solution was extracted with hexane to remove the excess of 2 . $\mathrm{MeOH}$ was then evaporated and $\mathrm{Et}_{2} \mathrm{O}$ was added, and the mixture was dried over $\mathrm{MgSO}_{4}$. After filtration and evaporation of $\mathrm{Et}_{2} \mathrm{O}$, 1t-PEO was obtained as a brownish viscous oil in $88 \%$ yield. ${ }^{1} \mathrm{H}$ NMR $\left(\mathrm{CDCl}_{3}, 400 \mathrm{MHz}\right): \delta 6.94(\mathrm{~d}, J=3.6 \mathrm{~Hz}, 1 \mathrm{H}), 6.86(\mathrm{~d}, J=$ $3.6 \mathrm{~Hz}, 1 \mathrm{H}), 4.34(\mathrm{~s}, 2 \mathrm{H}), 3.6\left(\mathrm{br}, \mathrm{OCH}_{2} \mathrm{CH}_{2} \mathrm{O}\right), 3.30(\mathrm{~s}, 3 \mathrm{H}$, $\left.\mathrm{OCH}_{3}\right), 2.33(\mathrm{t}, J=6.8 \mathrm{~Hz}, 2 \mathrm{H}), 1.51(\mathrm{~m}, 2 \mathrm{H}), 1.35(\mathrm{~m}, 2 \mathrm{H})$, $1.24(\mathrm{~m}, 4 \mathrm{H}), 0.82(\mathrm{t}, J=6.8 \mathrm{~Hz}, 3 \mathrm{H}) .{ }^{13} \mathrm{C} \mathrm{NMR}\left(\mathrm{CDCl}_{3}\right.$, $100 \mathrm{MHz}): \delta 131.6,130.1,125.4,121.8,95.5,89.1,79.1,73.1$, 71.8-69.2 $\left(\mathrm{OCH}_{2} \mathrm{CH}_{2} \mathrm{O}\right), 59.2,59.0,31.5,28.8,28.6,22.8,20.0$, 14.4. FAB-MS: $m / z$ : $987.7[\mathrm{M}+\mathrm{Na}]^{+}$(calcd 987.5).

2t-PEO. Refer to the procedure for the synthesis of 1t-PEO; 2t-PEO was obtained in $94 \%$ yield as a brownish viscous oil.
${ }^{1} \mathrm{H}$ NMR $\left(\mathrm{CDCl}_{3}, 400 \mathrm{MHz}\right): \delta 7.02(\mathrm{~m}, 1 \mathrm{H}), 6.91(\mathrm{~m}, 3 \mathrm{H})$, $4.37(\mathrm{~s}, 2 \mathrm{H}), 3.6\left(\mathrm{br}, \mathrm{OCH}_{2} \mathrm{CH}_{2} \mathrm{O}\right), 3.31\left(\mathrm{~s}, 3 \mathrm{H}, \mathrm{OCH}_{3}\right), 2.36$ $(\mathrm{t}, J=6.8 \mathrm{~Hz}, 2 \mathrm{H}), 1.53(\mathrm{~m}, 2 \mathrm{H}), 1.40(\mathrm{~m}, 2 \mathrm{H}), 1.32(\mathrm{~m}, 4$ $\mathrm{H}), 0.84(\mathrm{t}, J=6.8 \mathrm{~Hz}, 3 \mathrm{H}) \cdot{ }^{13} \mathrm{C} \mathrm{NMR}\left(\mathrm{CDCl}_{3}, 50 \mathrm{MHz}\right)$ : $\delta$ 138.2, 136.2, 133.1, 131.6, 123.7, 123.3, 121.2, 96.1, 90.3, 79.2, 73.3, 71.7-69.1 $\left(\mathrm{OCH}_{2} \mathrm{CH}_{2} \mathrm{O}\right), 59.1,58.8,31.1,28.4,28.2$, 22.4, 19.6, 13.9. FAB-MS: $m / z$ : $1069.6[\mathrm{M}+\mathrm{Na}]^{+}$(calcd 1069.5).

3t-PEO. Refer to the procedure for the synthesis of 1t-PEO; 3t-PEO was obtained in $85 \%$ yield as a brownish viscous oil. ${ }^{1} \mathrm{H}$ NMR $\left(\mathrm{CDCl}_{3}, 400 \mathrm{MHz}\right): \delta 7.05(\mathrm{~m}, 1 \mathrm{H}), 6.99(\mathrm{~m}, 2 \mathrm{H})$, $6.94(\mathrm{~m}, 3 \mathrm{H}), 4.40(\mathrm{~s}, 2 \mathrm{H}), 3.6\left(\mathrm{br}, \mathrm{OCH}_{2} \mathrm{CH}_{2} \mathrm{O}\right), 3.33$ (s, $3 \mathrm{H}$, $\left.\mathrm{OCH}_{3}\right), 2.38(\mathrm{t}, J=4.8 \mathrm{~Hz}, 2 \mathrm{H}), 1.55(\mathrm{~m}, 2 \mathrm{H}), 1.39(\mathrm{~m}, 2 \mathrm{H})$, $1.27(\mathrm{~m}, 4 \mathrm{H}), 0.86(\mathrm{t}, J=4.4 \mathrm{~Hz}, 3 \mathrm{H}) .{ }^{13} \mathrm{C} \mathrm{NMR}\left(\mathrm{CDCl}_{3}\right.$, $100 \mathrm{MHz}): \delta$ 138.3, 136.6, 135.4, 133.3, 131.7, 129.2, 129.1, $124.8,124.4,123.3,123.2,121.2,96.1,90.4,79.3,73.4,71.8-$ $69.2\left(\mathrm{OCH}_{2} \mathrm{CH}_{2} \mathrm{O}\right), 59.1,58.9,31.2,28.5,28.3,22.4,19.7,13.9$. FAB-MS: $m / z$ : $1151.6[\mathrm{M}+\mathrm{Na}]^{+}($calcd 1151.5).

\section{Typical procedure for the synthesis of mesostructured nanocomposites}

Mesostructured nanocomposites were prepared according to well-known procedures. ${ }^{20,21,24}$ Fluorescent surfactant 1t-PEO was used as a representative example to describe the synthetic procedure. Typically, 1t-PEO $(0.5 \mathrm{~g})$ was dissolved in distilled water $(25.0 \mathrm{~g})$ with vigorous stirring. $37 \% \mathrm{HCl}(2.8 \mathrm{~g})$ was added to the reaction mixture and the solution was stirred for $30 \mathrm{~min}$ at $30{ }^{\circ} \mathrm{C}$. Tetraethyl orthosilicate $(1.9 \mathrm{~g})$ was then added dropwise to the reaction mixture; the solution was then stirred at $30{ }^{\circ} \mathrm{C}$ for $24 \mathrm{~h}$ and divided into two parts. The yellow precipitate of the first part (called 1T hereafter) was collected by centrifugation and washed with distilled water several times and then dried under vacuum overnight. The second part, called 1Th hereafter, was subjected to hydrothermal treatment at $100{ }^{\circ} \mathrm{C}$ for an additional $24 \mathrm{~h}$ before recovery by centrifugation. The abbreviations 2T and 2Th represent nanocomposites using 2t-PEO as the structure-directing agents, and 3T and 3Th represent nanocomposites using 3t-PEO as the surfactants. Before measuring their structural and textural properties, all nanocomposites were calcined in air at $560{ }^{\circ} \mathrm{C}$ for $6 \mathrm{~h}$ to remove surfactants. In order to check the integrity of the fluorescent surfactants, we removed the surfactants by extraction at $70{ }^{\circ} \mathrm{C}$ in acidic ethanol. The supernatant was collected and dried under vacuum prior to NMR measurement.

\section{Results and discussion}

Our strategy was to design fluorescent surfactants by combining a hydrophobic molecule and a hydrophilic PEO segment and then use these directly to guide the synthesis of mesostructured nanocomposites. Scheme 1 shows the organic synthesis strategy. Hydrophobic molecules 2, 5 and 7 were prepared by multi-step synthesis procedures, including the Sonogashira reaction, iodination and the Suzuki-Miyaura reaction. ${ }^{29}$ On the other hand, the commercially available poly(ethylene glycol) monomethyl ether was deprotonated by sodium hydride in dried THF and then treated with propargyl bromide at room temperature to give the hydrophilic PEO segment with acetylenic end 


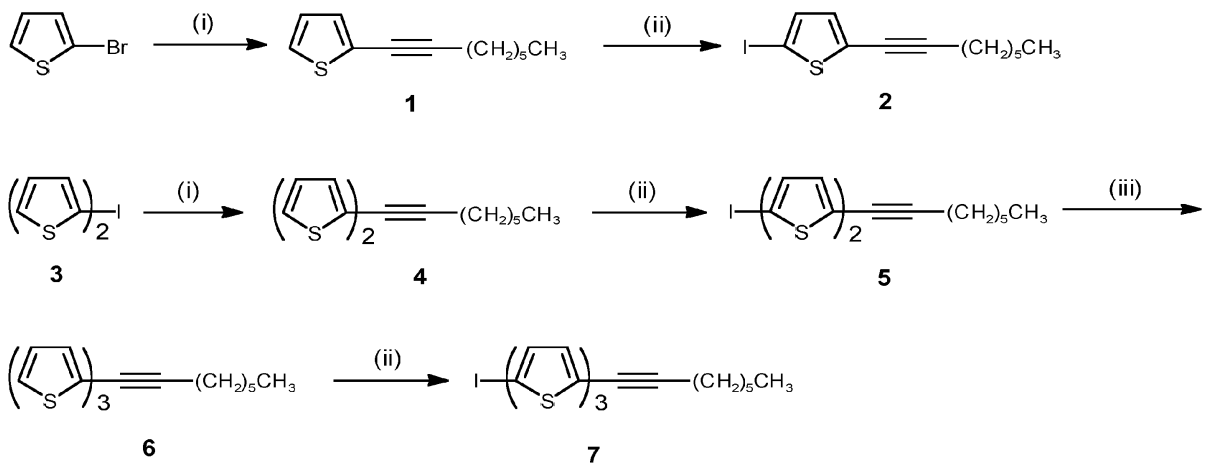

Hydrophilic portion

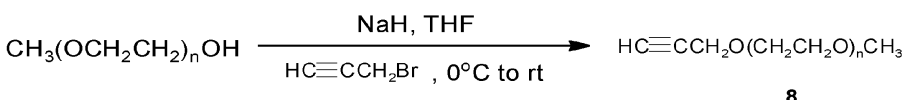

Formation of fluorescent surfactants

$1-C_{\mathrm{S}}=\left(\mathrm{CH}_{2}\right)_{5} \mathrm{CH}_{3}$

$1-\left(\left\langle I_{S}\right)_{2}=\left(\mathrm{CH}_{2}\right)_{5} \mathrm{CH}_{3}\right.$

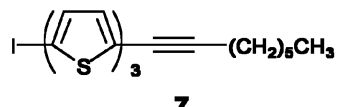

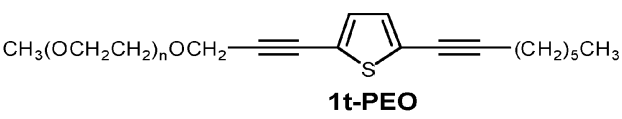

$\underset{\mathrm{THF}, \mathrm{Et}_{3} \mathrm{~N}, 40^{\circ} \mathrm{C}}{\stackrel{\text { 8, } \mathrm{Pd}\left(\mathrm{PPh}_{3}\right)_{4} / \mathrm{Cul}}{\longrightarrow}}$

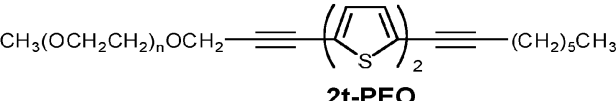

$\mathrm{CH}_{3}\left(\mathrm{OCH}_{2} \mathrm{CH}_{2}\right)_{\mathrm{n}} \mathrm{OCH}_{2}=(\sqrt{\mathrm{S}})_{3}=\left(\mathrm{CH}_{2}\right)_{5} \mathrm{CH}_{3}$

$n=16$

3t-PEO

Scheme 1 Synthetic strategy for the preparation of fluorescent surfactants. Reaction conditions: (i) 1-octyne, $\mathrm{Pd}\left(\mathrm{PPh}_{3}\right)_{4}, \mathrm{CuI}, \mathrm{THF}$ and $\mathrm{NEt}{ }_{3}$; (ii) (1) $n$ - $\mathrm{BuLi}$ and $\mathrm{Et}_{2} \mathrm{O}, 0{ }^{\circ} \mathrm{C}$ to rt; (2) $\mathrm{I}_{2},-78{ }^{\circ} \mathrm{C}$ to rt; (iii) $2-\mathrm{C}_{4} \mathrm{H}_{3} \mathrm{SB}(\mathrm{OH})_{2}, \mathrm{Pd}\left(\mathrm{PPh}_{3}\right)_{4}, \mathrm{~K}_{2} \mathrm{CO}_{3}, \mathrm{DME}$ and $\mathrm{H}_{2} \mathrm{O}$.

group $\mathbf{8}$. The reaction of $\mathbf{2}, \mathbf{5}$ and $\mathbf{7}$ with $\mathbf{8}$ via the Sonogashira coupling reaction gave the fluorescent surfactants 1t-PEO, 2t-PEO and 3t-PEO, respectively. The reaction can be easily monitored by observing the signals in the ${ }^{1} \mathrm{H}$ NMR spectra. Using 1t-PEO as an example, the doublet signal at $4.14 \mathrm{ppm}$ is due to the propargylic protons of 8 . After $12 \mathrm{~h}$, the signal at $4.14 \mathrm{ppm}$ had completely vanished and a new singlet appeared at $4.34 \mathrm{ppm}$, which is assigned to the propargylic protons of 1t-PEO, indicating the completion of the reaction. After cooling to room temperature, the pure surfactant was obtained in $88 \%$ yield by the usual workup procedures. Similarly, 2t-PEO and 3t-PEO were both obtained as brownish viscous oils in $94 \%$ and $85 \%$ yield, respectively. The surfactants obtained were used as templates for the preparation of mesostructured nanocomposites by the procedure described in the Experimental section.

Powder X-ray diffraction (XRD) patterns and transmission electron microscopy (TEM) images of a series of calcined nanocomposites with further hydrothermal treatment are shown in Fig. 1. All three samples (1Th-3Th) exhibited strong diffraction peaks at low angles, indicating the existence of an ordered mesostructure within these nanocomposites. From nanocomposites 1Th to 3Th, the hydrophobic chain length of the surfactants becomes longer and hence produces composites with larger
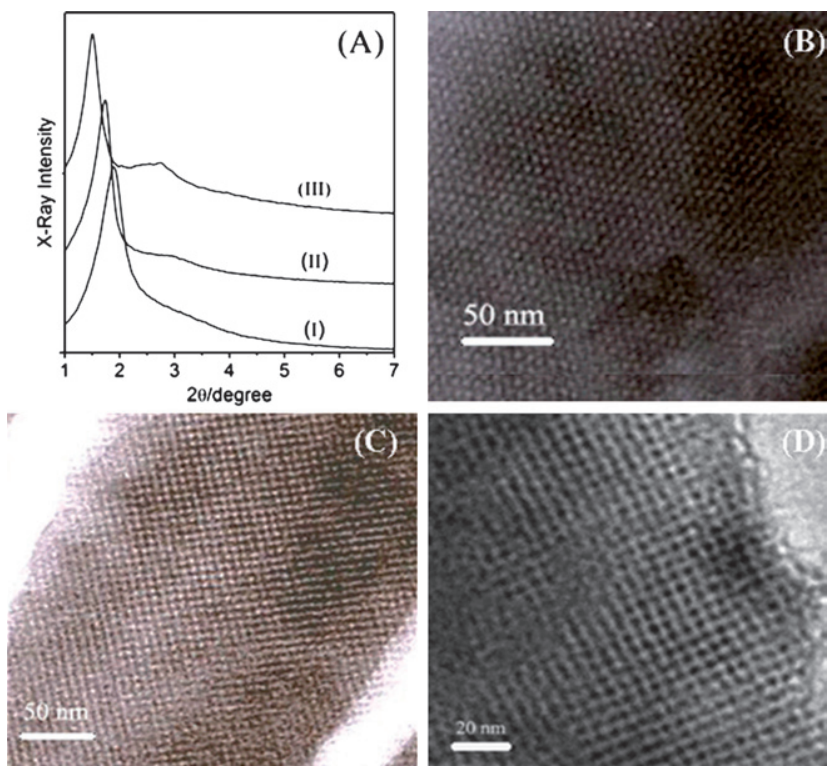

Fig. 1 (A) X-Ray diffraction (XRD) pattern of a series of mesostructured nanocomposites after calcination: (I) 1Th, (II) $2 \mathbf{T h}$ and (III) $3 \mathbf{T h}$. Representative TEM images of nanocomposites (B) $2 \mathbf{T h}$, (C) 3Th and (D) $3 \mathrm{Th}$ after calcination. 
Table 1 Structural and textural data of mesostructured nanocomposites ${ }^{a}$

\begin{tabular}{|c|c|c|c|c|c|c|c|c|c|}
\hline Sample & $S / \mathrm{m}^{2} \mathrm{~g}^{-1}$ & $d / \mathrm{nm}$ & $D_{\mathrm{p}} / \mathrm{nm}$ & $V_{\mathrm{t}} / \mathrm{cm}^{3} \mathrm{~g}^{-1}$ & Sample & $S / \mathrm{m}^{2} \mathrm{~g}^{-1}$ & $d / \mathrm{nm}$ & $D_{\mathrm{p}} / \mathrm{nm}$ & $V_{\mathrm{t}} / \mathrm{cm}^{3} \mathrm{~g}^{-1}$ \\
\hline $1 \mathrm{~T}$ & 683 & 4.07 & $<1.5$ & 0.36 & 1Th & 961 & 4.67 & 2.4 & 0.59 \\
\hline $2 \mathrm{~T}$ & 655 & 4.47 & 1.8 & 0.35 & $2 \mathrm{Th}$ & 931 & 5.10 & 2.9 & 0.63 \\
\hline
\end{tabular}

${ }^{a} S$ is the BET specific surface area, $d$ represents the lattice constant calculated from XRD data using the Bragg equation, $D_{\mathrm{p}}$ stands for the pore diameter assigned from the maximum on the $\mathrm{BJH}$ pore size distribution, and $V_{\mathrm{t}}$ is total pore volume.

lattice constants. The corresponding $d$-spacings are 4.67, 5.10 and $5.92 \mathrm{~nm}$ for 1Th, 2Th and 3Th, respectively. XRD patterns of nanocomposites without hydrothermal treatment (1T-3T), however, showed relatively broad diffraction peaks (not shown). Similarly, the same trend (longer hydrophobic chain length leading to nanocomposites with larger lattice constants) was also observed for 1T, 2T and 3T, as shown in Table 1.

TEM studies on these nanocomposites (1Th-3Th) showed the existence of an ordered mesostructure, in addition to providing direct evidence of the fluorescent surfactants in the role of structural-directing agents. The conjugated part of the surfactants are indeed located inside the mesoporous silicate nanochannels.

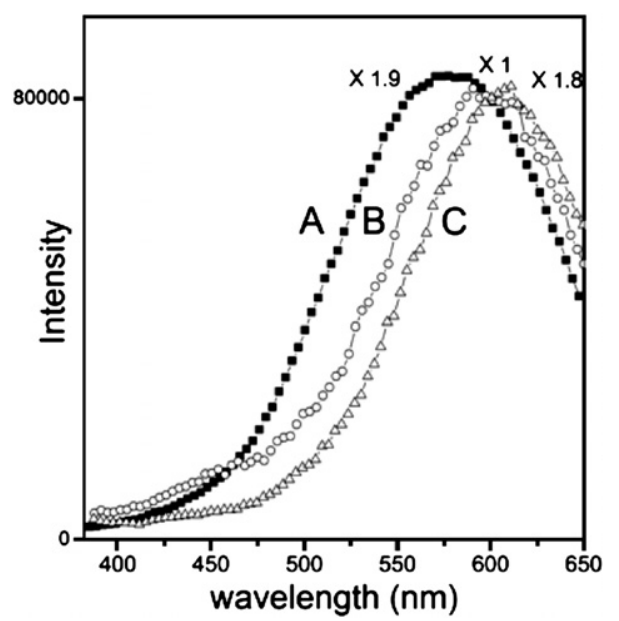

Fig. 2 Normalized fluorescence emission spectra of mesostructured nanocomposites: (A) 1Th, (B) 2Th and (C) 3Th.
Mesostructured nanocomposites with substantial pore filling of fluorophores were successfully prepared by one-step synthesis, which is an ideal system for studying the optical properties of fluorescent molecules in a confined space. As the fluorescent surfactants used in this report were of three different conjugation lengths, we expect the emission bands of these nanocomposites to be different. The successive order of the conjugation length of the surfactants is $3 \mathbf{T h}>\mathbf{2 T h}>\mathbf{1 T h}$, and hence the wavelength at the emission maximum of these nanocomposites should be $\mathbf{1 T h}<\mathbf{2 T h}<\mathbf{3 T h}$. After UV/Vis absorption measurement, we decided to use the excitation wavelengths $320 \mathrm{~nm}, 360 \mathrm{~nm}$ and $380 \mathrm{~nm}$ for $\mathbf{1 T h}, \mathbf{2 T h}$ and $3 \mathbf{T h}$, respectively. We measured the emission $\lambda_{\max }$ of each surfactant in THF solvent $\left(10^{-5} \mathrm{M}\right)$, which were found to be $360 \mathrm{~nm}, 418 \mathrm{~nm}$ and $442 \mathrm{~nm}$ for 1t-PEO, 2t-PEO and 3t-PEO, respectively. Fig. 2 shows the fluorescence spectra of the nanocomposites (1Th-3Th). A broad fluorescence band was observed for all these nanocomposites, and the emission $\lambda_{\max }$ of each sample is (A) $1 \mathrm{Th}: 577 \mathrm{~nm}$, (B) $2 \mathrm{Th}: 594 \mathrm{~nm}$, and (C) 3Th: $608 \mathrm{~nm}$. The successive red-shift of the fluorescence band is understandable and can be attributed to the increasing conjugation length from 1t-PEO to 3t-PEO surfactants.

Fig. 3 shows the fluorescence spectra of (A) 1t-PEO, (B) 2t-PEO and (C) 3t-PEO fluorescent surfactants in different forms: neat compound, mesostructured nanocomposites without hydrothermal treatment and with hydrothermal treatment. Successive red-shifts in the fluorescence spectra were clearly observed going from neat compound, to mesostructured nanocomposite without hydrothermal treatment, to mesostructured nanocomposite after hydrothermal treatment. Another experiment was performed in order to demonstrate the confinement effect. We physically blended the fluorescent surfactants with commercially available silica gel in $\mathrm{HCl}$ aqueous solution and
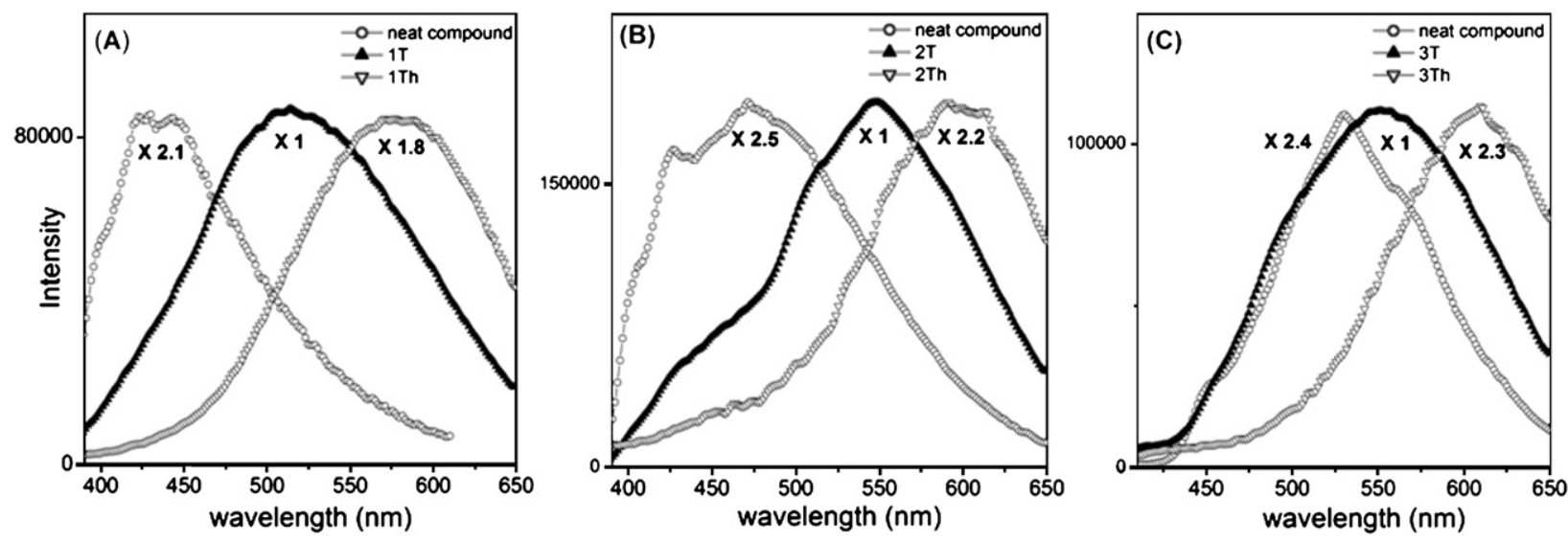

Fig. 3 Normalized fluorescence emission spectra of (A) 1t-PEO, (B) 2t-PEO and (C) 3t-PEO in different forms. 
found that even after hydrothermal treatment, there was no shift of the emission maximum when compared with pure surfactants. This result excludes the possibility that the red-shifted behavior shown in the fluorescence spectra was caused by the polar surface of silica species. Moreover, in order to check the integrity of our fluorescent surfactants, we collected the extractive products of these nanocomposites and measured their ${ }^{1} \mathrm{H}$ NMR spectra. For nanocomposites which have not undergone hydrothermal treatment (1T-3T), we found that these extractive products still exhibited characteristic ${ }^{1} \mathrm{H}$ NMR peaks that can be assigned to the pure surfactant. Take $\mathbf{2 T}$ as an example: two of the most crucial signals regarding the integrity of the surfactant - singlet peak at $4.37 \mathrm{ppm}$ and triplet signal at $2.36 \mathrm{ppm}-$ were still maintained. Besides, the signals belonging to the hydrophobic part of the surfactant such as the alkyne group and thiophene part were all observed and were identical to those of the pure surfactant. Nonetheless, for nanocomposites that have had hydrothermal treatment (1Th-3Th), there are slightly decreased ${ }^{1} \mathrm{H}$ NMR signals that are assigned to the thiophene protons, indicating that small amounts of the thiophene block might lose integrity. But the singlet signal at $4.37 \mathrm{ppm}$ and the triplet peak at $2.36 \mathrm{ppm}$ were still observed. If we take fluorescence intensity into consideration (Fig. 3), from 1t-PEO to 3t-PEO, the brightest samples are always the nanocomposites without hydrothermal treatment. As the pores are substantially filled up, one might expect considerable fluorescence self-quenching. Apparently, this is not the case. Our confined nanocomposites without hydrothermal treatment actually gave stronger fluorescence than the neat sample. ${ }^{18}$ Nanocomposites with hydrothermal treatment however showed a slightly decreased fluorescence intensity, which might due to the loss of some of thiophene's integrity.

Because the decrease of thiophene's proton signal is only slight, we assumed that the red-shifted behavior in the fluorescence spectra is mainly a result of the different ways of molecular packing. In fact, fluorescent surfactants should pack randomly and loosely when they are simply cast on the substrate (Fig. 3, neat compound). In contrast, in the case of mesostructured nanocomposites, these surfactants pack in an orderly and compact manner inside the nano-channels, which can be confirmed by TEM images and XRD data. There are a few previous reports that show the red-shifted fluorescence of conjugated polymers in a confined space or under a rigid environment. .,6,23,30 $^{-1}$

In comparison with nanocomposites that have not undergone hydrothermal treatment, hydrothermally treated nanocomposites showed fluorescence bands that are even more red-shifted. In order to elucidate the phenomenon, we calcined these nanocomposites and then used them in an $\mathrm{N}_{2}$ adsorption-desorption isotherm experiment. The calcined nanocomposites without hydrothermal treatment (1T-3T) displayed typical type IV $\mathrm{N}_{2}$ adsorption-desorption isotherms (Fig. 4(A)). The pore size distribution of these nanocomposites as analyzed by the BarrettJoyner-Halenda (BJH) method became smaller with decreasing hydrophobic chain length of the surfactants (Table 1). This result is consistent with XRD data, as larger lattice constant samples also have larger pore diameters. After $100{ }^{\circ} \mathrm{C}$ hydrothermal treatment (Fig. 4(B)), the mesopore size of each nanocomposite (1Th-3Th) increased by the substantial amount of $1 \mathrm{~nm}$, and the hysteresis loop of the adsorption-desorption curve is sharper
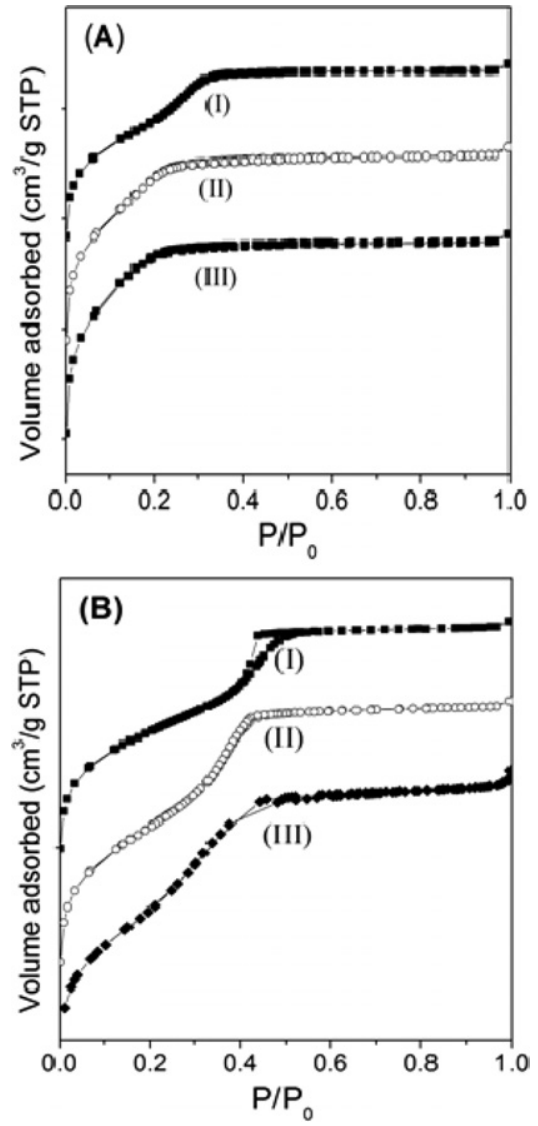

Fig. 4 Nitrogen adsorption-desorption isotherms of calcined mesostructured nanocomposites: (A) unhydrothermally treated 3T (I), 2T (II), and 1 T (III) and (B) hydrothermally treated 3Th (I), 2Th (II), and 1Th (III). (For clarity, the $y$-axis is not drawn to scale.)

than those of the nanocomposites without hydrothermal treatment, indicating a narrower pore size distribution. Table 1 listed the detailed textural and structural properties of each mesostructured nanocomposite.

In summarizing the above experimental observations, we now present some theoretical considerations in the interpretation of the spectra behavior. During the 1990s, in investigating the electronic structure of conjugated polymer systems, it was realized that inter-chain couplings could be very important in the delocalization polarons and could give rise to changes in spectra. ${ }^{31}$ It has been shown that regio-regular poly(3-hexylthiophene) can form nanocrystals with lamellar structures, ${ }^{32,33}$ where the inter-chain coupling is substantially increased; the polarons then become delocalized over several chains in the self-assembled lamellar structures. Theoretical investigation also showed that in the crystalline situation both the quasiparticle band gap and the exciton binding energies are drastically reduced in comparison with the isolated chain. ${ }^{34}$ This would lead to a red-shift of the emission. We studied the optical properties of single chains (in solution) versus coupled chains in the confined space of a nanocomposite and observed a strong red-shift in the photoluminescence spectra. This could be the consequence of a more ordered packing structure of the hydrophobic core in the nanocomposite. The better $\pi-\pi$ interaction between chains effectively results in an increased effective conjugation length and thus 


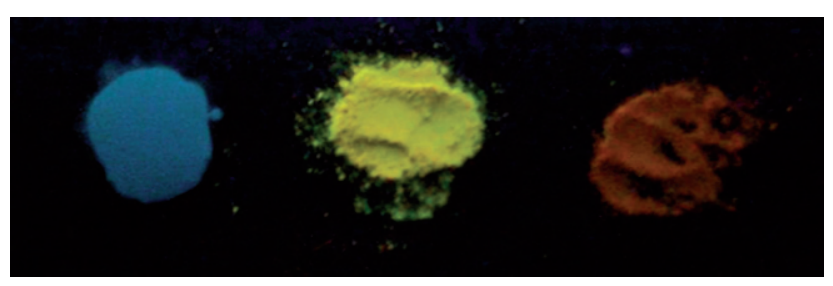

Fig. 5 Representative digital image of 2t-PEO fluorescent surfactants in neat form (left), 2T (middle), and 2Th (right), all taken under UV light $(\lambda=365 \mathrm{~nm})$.

leads to red-shifted spectra. Upon hydrothermal treatment, we observed a larger $d$-spacing $(\sim 0.6 \mathrm{~nm})$ and a very appreciable increase of pore size $(\sim 1 \mathrm{~nm}$; see Table 1$)$. The significant increase in pore size implies that the thiophene part of the core becomes more extended, which leads to better packing in the axial direction. The resulting stronger interchain coupling could explain the further red-shift of the emission spectra. We also note that from 1t-PEO to 3t-PEO, in the case of tri-thiophene, intrachain coupling dominates over inter-chain contributions. Thus, we see a smaller red-shift of the emission spectra there. We should note here that increased inter-chain coupling also results in dramatic changes in the Raman and IR spectra. ${ }^{35,36}$ This we plan to investigate in future work. It seems that our specially designed oligothiophenic surfactant/silica nanocomposite provides a unique system for studying the inter-chain coupling in a conjugated electronic system.

SBA-15 is a well known mesoporous structure that tends to increase in pore diameter after hydrothermal treatment. ${ }^{19,20,37}$ Previous research ${ }^{38}$ has suggested that the phenomenon of pore diameter expansion is related to the fact that PEO chains become more hydrophobic during hydrothermal treatment and thus rearrange themselves into the interior of the micelle. If this happens, the micelle volume and the pore diameter of resulting nanocomposites would inevitably be enlarged. Because the fluorescent surfactants used in our work also contain PEO chains, we believe that similar behavior would occur.

Fig. 5 shows representative digital images of 2t-PEO surfactants in (A) neat form, (B) nanocomposites without hydrothermal treatment, and $(\mathrm{C})$ nanocomposites with hydrothermal treatment under UV light $(\lambda=365 \mathrm{~nm})$. The fluorescence color of each sample can be easily distinguished with the naked eye. The fluorescence of neat surfactants is light blue; nanocomposites without hydrothermal treatment show yellow fluorescence; while orange fluorescence was observed in nanocomposites after hydrothermal treatment. In fact, this is what we observed in the fluorescence spectra (Fig. 3(B)). As our nanocomposite materials were synthesized by a sol-gel process, they could also be cast in a film-coating form. These mesoporous silica thin films would show strong photoluminescence, which may be very useful.

\section{Conclusions}

In conclusion, fluorescent surfactants of different conjugation lengths were successfully synthesized and used directly as templates to prepare mesostructured organic/inorganic nanocomposites, which showed fluorescence in the yellow and orange range. This result demonstrates the possibility of preparing nanocomposites with tunable optical properties. The resulting nanocomposites created by one-step synthesis could have both the desired ordered mesostructure and tunable fluorescence. The pore diameter of the resulting nanocomposites varied from $<1.5 \mathrm{~nm}$ to $3.2 \mathrm{~nm}$, depending on the surfactant used. In comparison with neat fluorescent surfactants, all the nanocomposites showed a remarkably red-shifted emission band in the fluorescence spectra. As only a small amount of thiophene's integrity was lost, we believe that this red-shifted phenomenon is mainly related to the inter-chain interaction, which may be controlled by chain packing in the nanochannels. Inside the nanochannels of mesostructured nanocomposites, the conjugated part of fluorescent surfactants is packed more compactly and completely than they would be if cast on the substrate. Combined with data from the $\mathrm{N}_{2}$ adsorption experiment, we found that rearrangements of the conjugated part of the surfactants did occur during hydrothermal treatment, and thus affected the final fluorescent properties of the nanocomposites. Furthermore, due to the ease of casting the materials into films, novel optoelectronic applications can be envisioned. Experiments in the fabrication of mesostructured organic/inorganic nanocomposite thin films are now in progress.

\section{Acknowledgements}

This research was financially supported by the National Science Council of Taiwan (NSC93-2113-M-027-006). We gratefully thank Prof. Shiuh-Tzung Liu (National Taiwan University) and Prof. Hong-Pin Lin (National Cheng Kung University) for their helpful suggestions.

\section{References}

1 H. Eckert and M. Ward, Chem. Mater., 2001, 13, 3059.

2 (a) T.-W. Lee, O.-O. Park, J. Yoon and J.-J. Kim, Adv. Mater., 2001, 13, 211; (b) D. J. Cardin, Adv. Mater., 2002, 14, 553; (c) C.-G. Wu and T. Bein, Science, 1994, 266, 1013.

3 B. J. Scott, G. Wirnsberger and G. D. Stucky, Chem. Mater., 2001, 13, 3140 .

4 (a) Y. D. Glinka, S.-H. Lin, L.-P. Hwang, Y.-T. Chen and N. H. Tolk, Phys. Rev. B, 2001, 64, 085421; (b) N. Ostapenko, G. Telbiz, V. Ilyin, S. Suto and A. Watanabe, Chem. Phys. Lett., 2004, 383, 456.

5 V. S.-Y. Lin, D. R. Radu, M.-K. Han, W. Deng, S. Kuroki, B. H. Shanks and M. Pruski, J. Am. Chem. Soc., 2002, 124, 9040.

6 T. Aida and K. Tajima, Angew. Chem., Int. Ed., 2001, 40, 3803.

7 (a) T.-Q. Nguyen, J. Wu, V. Doan, B. J. Schwartz and S. H. Tolbert, Science, 2000, 288, 652; (b) W. C. Molenkamp, M. Watanabe, H. Miyata and S. H. Tolbert, J. Am. Chem. Soc., 2004, 126, 4476.

8 M. Ogawa, T. Nakamura, J.-I. Mori and K. Kuroda, J. Phys. Chem. $B, 2000,104,8554$.

9 (a) R. Hernandez, A.-C. Franville, P. Minoofar, B. Dunn and J. I. Zink, J. Am. Chem. Soc., 2001, 123, 1248; (b) P. N. Minoofar, B. S. Dunn and J. I. Zink, J. Am. Chem. Soc., 2005, 127, 2656.

10 (a) F. Marlow, M. D. McGehee, D. Zhao, B. F. Chmelka and G. D. Stucky, Adv. Mater., 1999, 11, 632; (b) J. Loerke and F. Marlow, Adv. Mater., 2002, 14, 1745.

11 Y. Lu, Y. Yang, A. Sellinger, M. Lu, J. Huang, H. Fan, R. Haddad, G. Lopez, A. R. Burns, D. Y. Sasaki, J. Shelnutt and C. J. Brinker, Nature, 2001, 410, 913.

12 G. Li, S. Bhosale, T. Wang, Y. Zhang, H. Zhu and J.-H. Fuhrhop, Angew. Chem., Int. Ed., 2003, 42, 3818.

13 J.-L. Shi, Z.-L. Hua and L.-X. Zhang, J. Mater. Chem., 2004, 14, 795, and references therein.

14 G. Wirnsberger, B. J. Scott and G. D. Stucky, Chem. Commun., 2001, 119. 
15 H. Fan, Y. Lu, A. Stump, S. T. Reed, T. Baer, R. Schunk, V. Perez-Luna, G. P. Lopez and C. J. Brinker, Nature, 2000, 405, 56.

16 (a) A. Sellinger, P. M. Weiss, A. Nguyen, Y. Lu, R. A. Assink, W. Gong and C. J. Brinker, Nature, 1998, 394, 256; (b) C.-G. Wu and T. Bein, Science, 1994, 264, 1757; (c) K. Moller, T. Bein and R. X. Fischer, Chem. Mater., 1999, 11, 665; (d) K. Kageyama, J.-I. Tamazawa and T. Aida, Science, 1999, 285, 2113; (e) M. J. MacLachlan, P. Aroca, N. Coombs, I. Manners and G. A. Ozin, Adv. Mater., 1998, 10, 144.

17 A. P.-Z. Clark, K.-F. Shen, Y. F. Rubin and S. H. Tolbert, Nano Lett., 2005, 5, 1647.

18 C. J. Bhongale and C.-S. Hsu, Angew. Chem., Int. Ed., 2006, 45, 1404

19 D. Zhao, J. Feng, Q. Huo, N. Melosh, G. H. Fredrickson, B. F. Chmelka and G. D. Stucky, Science, 1998, 279, 548.

20 D. Zhao, Q. Huo, J. Feng, B. F. Chmelka and G. D. Stucky, J. Am. Chem. Soc., 1998, 120, 6024.

21 Y.-T. Chan, H.-P. Lin, C.-Y. Mou and S. T. Liu, Chem. Commun., 2002, 2878

22 M. A. Wahab and A. Sellinger, Chem. Lett., 2006, 35, 1240.

23 (a) J. Roncali, Chem. Rev., 1992, 92, 711; (b) J. Roncali, Chem. Rev. 1997, 97, 173.

24 F.-Y. Tsai, H.-L. Tu and C.-Y. Mou, J. Mater. Chem., 2006, 16, 348 .

25 (a) A.-L. Ding, J. Pei, Y.-H. Lai and W. Huang, J. Mater. Chem., 2001， 11，3082; (b) D. Beljonne, J. Cornil, R. H. Friend, R. A. J. Janssen and J. L. Brédas, J. Am. Chem. Soc., 1996, 118, 6453.
26 G. Zeni, C. W. Nogueira, R. B. Panatieri, D. O. Silva, P. H. Menezes, A. L. Braga, C. C. Silveira, H. A. Stefani and J. B. T. Rocha, Tetrahedron Lett., 2001, 42, 7921.

27 E. G. A. Notaras, N. T. Lucas and M. G. Humphrey, Organometallics, 2003, 22, 3659

28 D. A. Forsyth and D. E. Vogel, J. Org. Chem., 1979, 44, 3917.

29 L. Brandsma, S. F. Vasilevsky and H. D. Verkruijsse, Application of Transition Metal Catalysts in Organic Synthesis, Springer-Verlag, Berlin, 1998.

30 (a) L. Liao, Y. Pang and F. E. Karasz, Macromolecules, 2002, 35, 5720; (b) D. Oelkrug, A. Tompert, J. Gierschner, H.-J. Egelhaaf, M. Hanack, M. Hohloch and E. Steinhuber, J. Phys. Chem. B, 1998, 102, 1902.

31 J. A. Blackman and M. K. Sabra, Phys. Rev. B, 1993, 47, 15437.

32 T. A. Chen, X. Wu and R. D. Rieke, J. Am. Chem. Soc., 1995, 117, 233

33 T. J. Prosa, M. J. Vinokur and R. D. McCullough, Macromolecules, 1996, 29, 3654.

34 J.-W. van der Horst, P. A. Bobbert, P. H. L. de Jong, M. A. J. Michels, G. Brocks and P. J. Kelly, Phys. Rev. B, 1993, 47, 15817.

35 R. Oesterbacka, C. P. An, X. M. Jiang and Z. V. Vardeny, Synth. Met., 2001, 116, 317

36 F. C. Spano, J. Chem. Phys., 2005, 122, 234701.

37 P. Feng, X. Bu and D. J. Pine, Langmuir, 2000, 16, 5304

38 M. Impéror-Clerc, P. Davidson and A. Davidson, J. Am. Chem. Soc., 2000, 122, 11925. 